\title{
Comparative Research on Traditional Advertising and Mobile Phone Advertising
}

\author{
Qianyi Li ${ }^{1}$, Jing Huan ${ }^{1}$, Zhiqiang Luan ${ }^{2}$ \\ ${ }^{1}$ International College Beijing, China Agricultural University, Beijing, 100083, China \\ ${ }^{2}$ Accorsponding author, International College Beijing, China Agricultural University, Beijing, China \\ liqianyi100@sina.com, huanjing0805@sina.com, luanzhiqiang@cau.edu.cn
}

\begin{abstract}
Nowadays, the mobile advertising has a prevalent trend when comparing to the traditional advertising methods, for instance, the TV, radio and the Internet. Our research aims to find out how consumers perceive about the traditional and mobile advertising. More precisely, we downsize our project into a more specific one, which is comparison the advertisements of Jing Dong and Suning both from website and mobile phone, because they both have traditional and modern style of advertising. To deeply study influence of the mobile advertising on consumers' preference, we divide them into two categories, electrical equipment and non electrical, so that we could see the advertisements' strategies among different companies. In order to make the comparison more objectives, we also introduce some other renowned websites as parameters.
\end{abstract}

Index Terms - mobile advertising, e-business, advertising style, management innovation

\section{Introduction}

With the proliferation of the advertisements, the way people accessing to them are becoming more and more versatile. Apart from the traditional one, like the television advertising, radio advertising and newspaper advertising. The advertisements from the Internet, mobile phone and apps in the mobile are prevalent among different ages of people. As the mobile phones are utilized by more and more citizens and in a staggering rate, the mobile advertising found its market.

"Mobile advertising refers to advertisements sending and receiving by mobile devices, i.e. cellular phones, personal digital assistants, and other handled devices which people carry with them" [1]. It seems that the mobile advertising may have more advantages when comparing with the other traditional methods of advertising, such as the Internet, the TV and the radio. "Mobile advertising is perceived by many marketers to be more effective because it allows for a one-toone targeted interaction. According to Informa Telecoms \&Media, global mobile ad spending this year is projected to top $\$ 1.5$ billion, up to 42 percent from $\$ 871$ million in 2006 . This advertising offers small and medium-sized enterprises (MSEs) an opportunity for low cost marketing" [2]. While the mobile advertising in global has a predominant trend, China also experiences a growth on this field. The wide use of mobile messaging influences the improvement of m-commerce and mobile advertising.

Mobile advertisements are driven by SMS. In addition, "Color ringtones, WAP browsers, voice services are generating value for the end-users."'[3]. Mobile advertising can be spread upon the mobile apps which means that they won't meet the negotiation with operators, have no certification from app store, nor application container. "Mobile advertising can effectively work in any mobile product, not just a mobile web app" [3].

\section{Hypothesis}

The authors make the following hypothesis:

A. Jingdong and Suning have prevailing advantages on the mobile advertising.

B. Jingdong and Suning may be the most competitive rivals in all kinds of area, no matter the electrical or non-electrical equipment.

C. Taobao may be good at attracting consumers when purchasing the non-electronic equipments.

D. The consumers' satisfaction or preferences among the different websites can be determined by various aspects.

\section{Research Methods}

The authors use the Questionnaire to do the research, then use the SPSS application to analyze our data collected by the questionnaire which we delivered to the campus, companies and website.

The questions in our questionnaire are as follows, and we sent them to different age people in different area, like the universities, the companies, and also online. Our sample is 1000 .
A. Age
B. Gender
C. Large household equipment to buy
D. Non electrical equipment to buy
E. Delivery speed
F. Received most
G. Access to know the advertising
H. Access to receive advertising
I. How much advertising is reasonable
J. Which time of period is reasonable

\section{Data Analysis and Discussion}

We use the SPSS application to analyze our data collected by the questionnaire which we delivered to the campus, companies and website.

Citizens prefer going shopping online. So, we find that when buying large household appliances, consumers choose Jingdong most, more than 55\%. Besides, Suning appeals $20 \%$ 
of consumers to purchase. The other companies called Dazhong, Gome, Taobao and Amazon only account for less than $10 \%$ of the consumers each. When it comes to the non electrical equipment, there is a total difference. We predict there will be a competition between Suning and Jing Dong, but actually the competition between Jing Dong and Taobao are more stinging. There are more people fond of Taobao, about $70 \%$, when they prefer not to buy large household appliances.

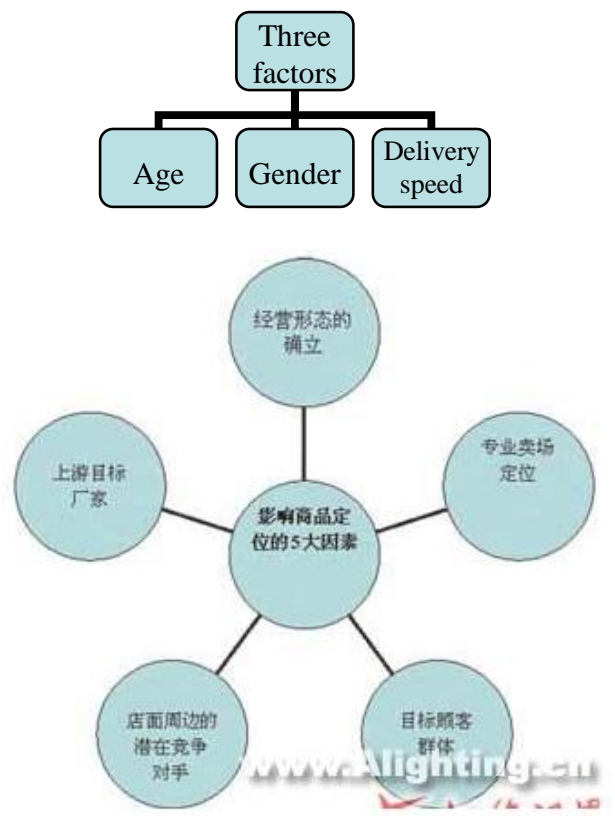

Fig. 1 Factors effect

In order to do in-depth research, we also consider several factors into consideration. First of all is the age factor. We find that large household appliances have a wide range of distribution. More than a half of the consumers choose the Jingdong, and the $30 \%$ of those are the teenagers between 1020 years old. And people aged from 10-30 years old would like to choose Suning and Jingdong. Furthermore, the Taobao, which has the less competitive rival of Jingdong in large appliance area, shows a quite different proportions, with only consumers under 40 years old choosing it. However, for the non electrical equipment, more youngsters are interested in buying products from Taobao, especially for the people among 10 to 30 years old. But it is interested to see that there are still some people sticking to Jingdong when buying non electrical products, the age are spread widely from 10 to 50, maybe because elderly people are trust Jingdong more than Taobao.

The second factor is gender, for the perception of choosing the website when purchasing the large household appliances, approximately $80 \%$ of the consumers are satisfied with products of Jingdong and Suning. The female consumers of Jingdong show more satisfaction on it while the Suning receives the corresponding percentage of the male and female consumers. As for the Taobao, the male consumers are more satisfied with the products than that of female. Conversely, there is an opposite trend for non household appliances. More men are likely to purchase on Jing Dong website than women, while women are seem like Taobao the best.

The third factor is the delivery speed, those who want to buy large household equipment or non electrical equipment show their satisfactions to Jingdong, no matter male or female. Meanwhile, the Amazon gains the second stage for the most satisfied. And we think Taobao should improve its delivery standard to be more competitive. Furthermore, DangDang, Taobao and Vancl only attained little amount of satisfaction.

We find that nowadays, with the greatest improvement in technology, receiving advertisements by mobile is quite common. Then we made research deeply about the mobile advertising methods utilized by the companies. Although we mentioned before that most customers receive ads about Taobao from the mobile, it seems that the Jingdong has more methods on mobile advertising when comparing to Taobao in large household appliances adertising. Jingdong and Suning truly play a prevailing role in the mobile advertising as we have forecast, both of them hold a large amount of the messages, and Jingdong is especially good at this field, with equally leading role in the multimedia message, emails from mobile and mobile applications. Besides, the winner of the receiving mobile ads most, Taobao, has less strategies on mobile advertising, which still depend on messages. We still want to look the way how companies send advertisements on non electrical equipment will have an effect. Almost every company pays much attention on the websites, like Jing Dong, Taobao, Amazon and Dang Dang, but a few companies could develop their mobile phone advertising, such as Jing Dong, Taobao and Dang Dang, so this will make them more acceptable than others. Taobao was changing its strategy in the non electrical equipment aspect.

When comparing traditional method, for instance, the newspaper and TV, with the mobile advertising. The result demonstrates that the portals still occupy the majority, and which was followed by the messages, for about $40 \%$. The TV plays a key role in delivering advertisement while the applications on mobile phones become more popular, which holds almost the same percentage with the TV. The newspaper, outdoor advertising and leaflets are merely accounting for a little part.

More specifically, we can get more details for companies' strategies. Suning's advertisement strategy is based on multimedia messages, while Taobao focuses more on text messages. In addition, Taobao and Dangdang are both provide sending advertisements to customers' email boxes. Jing Dong is good at developing advertisements for apps. When people answering the phone calls, almost are calling by Taobao. So we know that the reason why both Jing Dong and Taobao are prevalent among customers is partly because the advertisements they did was access to all different field, which makes customers more familiar to their brands. 


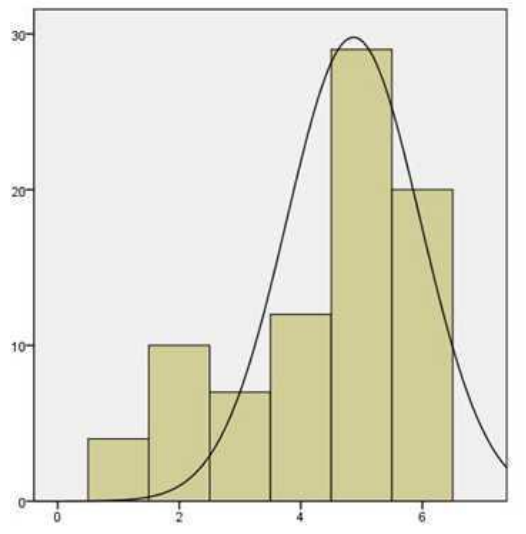

Std. Dev $=1.495$

Mean $=4.37$

$\mathrm{N}=100$

1: $6: 00-8: 00$

2: $8: 00-12: 00$

$3: 12: 00-14: 00$

4: $14: 00-18: 00$

5:18:00-22:00

6: every time is accepted

Fig. 2 Reasonable Time to Receive Mobile Phone Advertising

In order to help the government to administer the junk mobile phone advertising, we asked the question that if people have to receive mobile phone advertising, which time of period and how many of it is reasonable. The results are as follows. We can see from Fig. 2, most people think 18:0022:00 is reasonable, because they will relax at that time, and the advertisements will not disturb their study, work or even sleep. And this also can be a advise to companies for choosing a right time to send advertisements if they want to get a high response rate. When it comes to the quantity, more than $60 \%$ of the consumers prefer receiving 1 to 2 pieces of messages every day. And $10 \%$ of those would like $3-4$ pieces, with 5\% show that they do not care the exact amount.

\section{Conclusions}

As we separated the advertisement people received into two categories, large household appliances and non household appliances, and we want to see people's preference to each advertisement's source. From the data we analyzed above, we can reach a conclusion, for large household appliances, individuals are more likely to purchase them from Jing Dong website for its highest delivery speed, while for non electrical equipment, citizens prefer shopping online from Taobao website better because its name is popular to the customers, different from what we have assumed. The hypothesis we made before is that there will be a stiff competition between Sunning and Jing Dong, but actually, Jing Dong and Taobao are more competitive for their own field respectively, Suning is not that competitive with Jingdong. Furthermore, the comparison between traditional advertising and new kind of advertising, like the network advertising and mobile phone advertising are obviously. According to our data, apart from the network advertising, mobile phone advertising will be prevalent in the future, especially for the text messages and apps advertising from the mobile phone. But at the same time, we allocate that the government should make stringent policies to prevent junk mobile phone advertising from disturbing residents' regular life, may be the government could only allow the advertisements sending in a specific period of time, and the time period should be reasonable. All in all, there is still a long way to go for a well-organized advertising system.

\section{References}

[1] Sandra Soroa Koury (2007), Consumers' Responses to Mobile Advertising: A Normative Social Behavior [Online], Available from: http://books.google.com.hk/books?id=Yxz20BriBaEC \&printsec=frontco ver $\& \mathrm{dq}=$ mobile + advertising $\& \mathrm{hl}=\mathrm{zh}-$ $\mathrm{CN} \& \mathrm{sa}=\mathrm{X} \&$ ei $=$ FWqjUZ3CNsb4kgXisIDoBg\&ved=0CDYQ6AEwAQ

[2] Patricia OrdóñEz de Pablo (2009), The China information technology handbook [Online], Available from:

http://books.google.com.hk/books?id=9d95o_Rf_A0C\&pg=PA306\&dq $=$ mobile+advertising + in + China $\&$ hl $=$ zh-

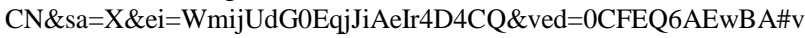
$=$ onepage $\& \mathrm{q}=$ mobile $\% 20$ advertising $\% 20 \mathrm{in} \% 20 \mathrm{China} \& \mathrm{f}=$ false

[3] Brian Fling (2009), Mobile Design and Development: Practical concepts and techniques for creating mobile sites and web apps [Online], Available from:

http://books.google.com.hk/books?id=LyMeulBTkH0C\&dq=mobile+ad vertising++apps\&hl=zh-CN\&source=gbs_navlinks_s

[4] Youngsok Bang, Dong-Joo Lee, Kunsoo Han, Minha Hwang, Jae-Hyeon Ahn (2013), Journal of Management Information Systems. Vol. 30 Issue 2, p101-126. 26p. 2

[5] Sevtap Ünal, Aysel Ercis, Ercan Keser (2011), International Strategic Management Conference. Procedia - Social and Behavioral Sciences. 24:361-377

[6] Qin Gao, Rau Pei-Luen Patrick, Salvendy Gavriel (2010). Behaviour \& Information Technology. Vol. 29 Issue 1, p35-44. 10p 